\title{
Direct oral anticoagulants in patients with chronic kidney disease: patient selection and special considerations
}

This article was published in the following Dove Press journal: International Journal of Nephrology and Renovascular Disease 12 June 2017

Number of times this article has been viewed

\author{
Jens Lutz' \\ Kerstin Jurk ${ }^{2}$ \\ Helmut Schinzel ${ }^{3}$ \\ 'Nephrology Department, \\ I. Medizinische Klinik und Poliklinik, \\ ${ }^{2}$ Center for Thrombosis and \\ Hemostasis, Universitätsmedizin \\ Mainz, ${ }^{3}$ Cardiopraxis Mainz, \\ Gerinnungsambulanz, MED \\ Facharztzentrum, Mainz, Germany
}

\begin{abstract}
Many patients with chronic kidney disease (CKD) receive anticoagulation or antiplatelet therapy due to atrial fibrillation, coronary artery disease, thromboembolic disease, or peripheral artery disease. The treatment usually includes vitamin $\mathrm{K}$ antagonists (VKAs) and/or platelet aggregation inhibitors. The direct oral anticoagulants (DOAC) inhibiting factor Xa or thrombin represent an alternative for VKAs. In patients with acute and chronic kidney disease, caution is warranted, as DOACs can accumulate as they are partly eliminated by the kidneys. Thus, they can potentially increase the bleeding risk in patients with CKD. In patients with an estimated glomerular filtration rate (eGFR) above $60 \mathrm{~mL} / \mathrm{min}$, DOACs can be used safely with greater efficacy and safety as compared to VKAs. In patients with CKD 3, DOACs are as effective as VKAs with a lower bleeding rate. The more the renal function declines, the lower is the advantage of DOACs over VKAs. Thus, use of DOACs should be avoided in patients with an eGFR below $30 \mathrm{~mL} / \mathrm{min}$, particularly, the compounds with a high renal elimination. Available data suggest that DOACs can also be used safely in older patients. In this review, use of DOACs in comparison with VKAs, heparins, and heparinoids, together with special considerations in patients with impaired renal function will be discussed.
\end{abstract}

Keywords: chronic renal disease, anticoagulation, renal function, vitamin K antagonists, bleeding, atrial fibrillation, dosing

\section{Introduction}

Patients with chronic kidney disease (CKD) have an increased risk for bleeding and thromboembolic complications. Uremic toxins, anemia, as well as hemodialysis (HD) affect coagulation, platelet function, and platelet-vessel wall interaction. ${ }^{1}$ The risk for thromboembolic disease is 2.5 times increased in mild renal dysfunction, while it is 5.5 times increased in severe renal dysfunction. ${ }^{2}$ The risk for thromboembolic diseases in patients with CKD further increases if concomitant morbidities such as arterial thrombosis (odds ratio [OR]: 4.9), malignant tumors (OR: 5.8), surgical procedures (OR: 14.0), or thrombophilia (OR: 4.3) are present. The incidence rate of primary/secondary venous thrombosis is $0.7 / 1.2$ (glomerular filtration rate [GFR] 60-89 $\mathrm{mL} / \mathrm{min}$ ) and 2.0/2.5 (GFR $15-59 \mathrm{~mL} / \mathrm{min}$ ), as compared to $0.6 / 0.8$ per 1000 person-years in patients without renal failure. ${ }^{3}$

The accumulation of uremic toxins during uremia itself can lead to bleeding episodes. ${ }^{4}$ Bleeding episodes occur in $24 \%-50 \%$ of HD patients. ${ }^{5-7}$ A hospitalbased analysis reported a $\sim 2$-fold increased risk of bleeding in patients with renal failure. ${ }^{8}$ The risk of bleeding related to advanced CKD (stage 4-5) further rises if
Section of Nephrology, I. Medizinische

Klinik und Poliklinik, Universitätsmedizin

Mainz, Langenbeckstr I, 55I3I Mainz,

Germany

Tel +496131172462

Fax +496131178471

Email jens.lutz@unimedizin-mainz.de 
patients receive anticoagulation therapy for the prevention of thromboembolic events such as pulmonary embolism or atrial fibrillation (AF) or particularly, if they receive anticoagulants and combinations of platelet aggregation inhibitors. ${ }^{9}$ Patients with advanced CKD (3-5) have an increased risk for AF, leading to an increased incidence of thromboembolic insults which occurred in $12 \%-72 \%$ and in $3 \%-13 \%$ of patients with a creatinine clearance $(\mathrm{CrCl})$ below $60 \mathrm{~mL} / \mathrm{min}$ and below $30 \mathrm{~mL} / \mathrm{min}$, respectively. ${ }^{10}$ Thus, a moderately/severely reduced GFR is a predictor for mortality as well as for bleeding episodes with anticoagulants. ${ }^{10-12}$ Anticoagulation therapy in CKD patients can promote bleeding episodes, as these substances can accumulate or directly interfere with an already changed hemostatic system. ${ }^{13}$ Anticoagulants that can accumulate in patients with renal impairment include low-molecularweight heparins (LMWH), danaparoid, fondaparinux, and direct oral anticoagulants (DOAC) such as rivaroxaban, edoxaban, apixaban, or dabigatran (Table 1) as well as the direct thrombin inhibitor argatroban. Thus, special consideration of the renal function is warranted in patients treated with these substances.

\section{Anticoagulation with vitamin $\mathrm{K}$ antagonists, heparins, or heparinoids in CKDs}

AF, pulmonary embolism, vascular occlusive diseases, vascular bypasses, as well as hereditary thrombophilic disorders (in the presence of additional risk factors) are the

Table I DOACs in patients with advanced CKD

\begin{tabular}{|c|c|c|}
\hline & Dosage & Comment \\
\hline \multicolumn{3}{|c|}{ Direct factor $\mathrm{Xa}$ inhibitors } \\
\hline Apixaban & $\begin{array}{l}\text { eGFR } 30-49 \mathrm{~mL} / \mathrm{min}: 2 \times 5 \mathrm{mg} / \mathrm{d} \\
\text { If }>\text { I additional criteria age } \\
>80 \text { years, body weight }<60 \mathrm{~kg} \text {, } \\
\text { creatinine }>1.5 \mathrm{mg} / \mathrm{dL}: 2 \times 2.5 \mathrm{mg} / \mathrm{d}\end{array}$ & Renal elimination $27 \%$ \\
\hline Rivaroxaban & eGFR $30-49 \mathrm{~mL} / \mathrm{min}: 10 \mathrm{mg} / \mathrm{d}$ & Renal elimination $33 \%$ \\
\hline Edoxaban & eGFR I5-50 mL/min: $30 \mathrm{mg} / \mathrm{d}$ & $\begin{array}{l}\text { Renal elimination } 50 \% \text {, } \\
\text { not recommended if } \\
\text { eGFR }<30 \mathrm{~mL} / \mathrm{min}\end{array}$ \\
\hline \multicolumn{3}{|c|}{ Direct thrombin inhibitors } \\
\hline Dabigatran & eGFR >60 mL/min: $2 \times 150 \mathrm{mg} / \mathrm{d}$ & $\begin{array}{l}\text { Not recommended } \\
\text { if eGFR }<60 \mathrm{~mL} / \mathrm{min} \text {; } \\
\text { contraindicated if } \\
\text { eGFR }<30 \mathrm{~mL} / \mathrm{min} \text {; } \\
\text { renal elimination } 80 \%\end{array}$ \\
\hline
\end{tabular}

Note: Most data are derived from studies in patients with AF. The dosages for patients with advanced CKD and venous thromboembolism or AF are similar. $^{31,35-38,40,41,68,75,76}$

Abbreviations: AF, atrial fibrillation; CKD, chronic kidney disease; DOACs, direct oral anticoagulants; eGFR, estimated glomerular filtration rate. principal indications for anticoagulation therapy in patients with CKD. ${ }^{14,15}$

Vitamin $\mathrm{K}$ antagonists (VKA) are the cornerstone of anticoagulation therapy. A retrospective cohort study in older patients with $\mathrm{AF}$ and reduced renal function revealed that VKA significantly reduced the risk of all-cause death, ischemic stroke, or transient ischemic attack, as compared to no treatment. ${ }^{16}$ Treatment with VKA is associated with a substantial bleeding risk that is also related to the reduced renal function as described above. Therapy with VKA is more difficult in advanced CKD patients or patients on dialysis, as the international normalized ratio (INR) is often outside the therapeutic range, which can be related to an underlying vitamin $\mathrm{K}$ deficit as well as adherence difficulties. ${ }^{17,18}$ Another objection to the treatment with VKA in patients with CKD is the association of VKA with vascular calcification including calciphylaxis (subcutaneous arteriolar calcification). ${ }^{19-21}$ Some studies also showed an increased risk for strokes and bleeding in patients with severe renal impairment and VKA therapy related to AF. A retrospective analysis in dialysis patients with AF showed that treatment with warfarin was associated with an increased rate of strokes. However, this was dependent on INR-monitoring, as patients without an adequate INR monitoring during the first 90 days after treatment initiation had significantly increased risk for strokes as compared to patients without warfarin treatment. ${ }^{22}$

Another report from the Dialysis Outcomes and Practice Patterns Study data described that warfarin in patients with dialysis and $\mathrm{AF}$ was associated with an increased incidence of stroke, as compared to dialysis patients not on warfarin. ${ }^{23}$ The risk was particularly increased in patients older than 75 years. Another analysis in dialysis patients with AF demonstrated a $44 \%$ increased risk of bleeding with a comparable risk of strokes in patients on warfarin, as compared to patients not on warfarin..$^{24}$ Again, interpretation of the data is difficult as the INR levels were not reported. Altogether, therapeutic monitoring with a stable INR within the therapeutic range seems to be of crucial importance. Instead of considering INR values alone, the time in the therapeutic range (TTR) according to the calculation of Rosendaal et al should be preferred in order to control the quality of anticoagulation with VKA. ${ }^{25}$ The TTR should be above $65 \%$, which is difficult to achieve in clinical routine. ${ }^{26}$

Heparins as well as heparinoids can also be used in patients with impaired renal function. Elimination of unfractionated heparin is independent of the renal function. On the other hand, hemorrhage, osteoporosis, or heparin-induced thrombocytopenia may result from the treatment with 
unfractionated heparin. LMWH and heparinoids are eliminated by the kidney. Thus, caution is warranted in patients with impaired renal function.

LMWHs have the potential to accumulate in renal failure as they depend on renal elimination and can lead to bleeding complications in patients with CKD 4-5. ${ }^{27,28}$ Certoparin, nadroparin, reviparin, danaparoid, and fondaparinux are not recommended or contraindicated in patients with a GFR $<30$ $\mathrm{mL} / \mathrm{min} .{ }^{10}$ Enoxaparin, nadroparin, dalteparin, and tinzaparin may be used with caution and dose adaptation for anticoagulation during HD.

Particularly in patients with end-stage renal disease (ESRD), the indication and the benefit risk ratio of anticoagulation therapy, particularly with VKA, is often not clear, as randomized controlled trials (RCTs) usually exclude patients with ESRD. Thus, data are derived from retrospective or registry analyses, which make it difficult to give clear recommendations, particularly for patients with advanced CKD. ${ }^{29}$ It seems that in patients with a good therapeutic control and a TTR over $75 \%$, VKA can be safely used. ${ }^{30}$

\section{Direct oral anticoagulants}

The introduction of direct oral inhibitors of factor $\mathrm{Xa}$ (apixaban, edoxaban, rivaroxaban) and thrombin (dabigatran) widened the options for anticoagulation treatment. These compounds are generally referred to as DOAC. As these compounds are eliminated by the kidneys, caution is warranted in patients with renal impairment (Table 1). ${ }^{31}$ Dosing relies on the estimation of GFR, which is dependent on the formula used. Thus, also, the adjusted dose of the DOAC in relation to the renal function differs in dependence to the equation used to estimate the GFR. The dosing recommendations of the DOAC based on the available data are summarized in Table 1. It is clear that estimating and monitoring of renal function is a key issue in the treatment with DOAC. Of note, all studies on DOAC used the estimated $\mathrm{CrCl}$ calculated by the Cockcroft-Gault formula. It is well known that this formula results in an overestimation of the renal function, particularly in advanced CKD with lower GFR rates. A reclassification of the CKD patients in the RE-LY and ARISTOTLE studies using the CKD epi formula led to similar results in the RE-LY study with dabigatran versus warfarin in patients with $\mathrm{AF} .{ }^{32}$ However, in the ARISTOTLE study, apixaban was significantly better as compared to warfarin with respect to the prevention of stroke and major bleeding. ${ }^{33}$

DOACs are advantageous in reducing thromboembolic events as well as bleeding episodes, as compared to warfarin. ${ }^{32-38}$ An analysis of 12 articles regarding major bleeding outcomes in patients with AF and non-ESRD on warfarin or DOAC revealed that a composite of major bleeding outcomes was reduced by $19 \%$ in patients randomized to DOAC as compared to dose-adjusted warfarin from the pooled data of three RCTs. ${ }^{39}$ The lower bleeding risk of DOAC as compared to warfarin was maintained until the renal function was severely impaired.

Furthermore, the mortality also could be reduced. But this could only be demonstrated in patients with a moderately reduced renal function and after dose adaptation. The more the renal function is impaired, the more the advantages of DOAC seem to decline as compared to VKAs. Data in patients with severely reduced renal function or those who are on dialysis are scarce. Patients with a GFR $<30 \mathrm{~mL} /$ min were excluded from the RE-LY trial (dabigatran), ${ }^{34}$ from the ROCKET AF/J-ROCKET AF (rivaroxaban), ${ }^{35,37}$ and from the ENGAGE-AF (edoxaban) trials. ${ }^{38}$ Patients with a GFR $<25 \mathrm{~mL} / \mathrm{min}$ or serum creatinine $>2.5 \mathrm{mg} / \mathrm{mL}$ were excluded from the ARISTOTLE (apixaban) ${ }^{36}$ and AVERROES (apixaban) ${ }^{40}$ trials. A meta-analysis of patients with a moderately reduced $\mathrm{CrCl}$ of $30-50 \mathrm{~mL} / \mathrm{min}$ demonstrated no significant differences in strokes and systemic thromboembolism as well as recurrent thromboembolism or thromboembolism-related death with DOAC as compared to VKA. The risk of major bleeding or the combined endpoint of major bleeding or clinically relevant non-major bleeding was similar between the groups. ${ }^{41}$ A population-based nested case-control study in older patients with moderate CKD not on dialysis showed an increased risk for hemorrhage and that exposure to dabigatran or rivaroxaban was not associated with a statistically significant increased risk of major hemorrhagic events as compared to warfarin. ${ }^{42}$ A limitation of the study was that only an algorithm was used to detect patients with CKD with missing individual GFR estimations.

A recently published meta-analysis compared the treatment with dabigatran, rivaroxaban, edoxaban, and apixaban in $\sim 14,000$ patients with AF and moderate CKD with respect to efficacy and safety, respectively. In this group of patients, the use of DOAC was related to a significant reduction of strokes and systemic embolism together with a better safety profile with respect to major bleeding as compared to warfarin. From a combined efficacy and safety point of view, apixaban and edoxaban were better as compared to dabigatran and rivaroxaban. ${ }^{43}$

So far, no outcome results of DOAC in patients with CKD stage 4 and 5 with AF are available. Thus, clear 
evidence-based recommendations for patients with severely reduced GFR ( $<30 \mathrm{~mL} / \mathrm{min}$ ) on dosing and the indication of DOACs could not be given so far.

\section{Direct oral factor Xa inhibitors}

\section{Apixaban}

The renal elimination of apixaban is $27 \%$, which is the lowest among the DOACs. ${ }^{44}$ It is eliminated by oxidative metabolism, renal, and intestinal routes. In the ARISTOTLE trial, patients with a serum creatinine level of $1.5 \mathrm{mg} / \mathrm{dL}$ and atrial fibrillation (AF) received a reduced dose of $2 \times 2.5 \mathrm{mg} / \mathrm{d}$ (standard dose $2 \times 5 \mathrm{mg} / \mathrm{d}$ ). Patients with a GFR below $25 \mathrm{~mL} / \mathrm{min}$ or a serum creatinine above $2.5 \mathrm{mg} / \mathrm{dL}$ were excluded from the study; $20 \%$ of the study population had a $\mathrm{CrCl}>50 \mathrm{~mL} / \mathrm{min}$. Bleeding episodes were higher in patients with moderate/severe renal impairment as compared to those with a normal renal function (from 1.5 to 3.2 per 100 patient-years for apixaban-treated patients and from 1.8 to 6.4 per 100 patient-years for warfarin-treated patients), but were lower with apixaban in comparison to warfarin in patients with renal impairment. ${ }^{36}$ A subgroup analysis in the CKD patients of the ARISTOTLE trial revealed that bleeding episodes and cardiovascular events were higher with an impaired renal function. However, apixaban reduced stroke, embolism, and mortality more than warfarin in patients with mild/ moderate $\mathrm{CKD}^{33}$

In the AMPLIFY trial investigating the treatment of acute venous thromboembolism (VTE) with apixaban versus enoxaparin/warfarin, renal impairment ( $7 \%$ of the study population with a $\mathrm{CrCl}<50 \mathrm{~mL} / \mathrm{min}$ ) was associated with more VTE or VTE-related death and major bleeding events. ${ }^{45}$ The safety benefit of apixaban diminished in patients with renal impairment, while the renal function did not affect the primary efficacy.

\section{Rivaroxaban}

The liver metabolizes two-thirds of the dose of rivaroxaban by cytochrome P450 (CYP) enzymes (CYP3A4, CYP2J2, and CYP-independent mechanisms), of which half is eliminated through the kidneys and the other half by the fecal route. Furthermore, one-third of the dose is eliminated by the kidneys as non-metabolized drug. The area under the curve increased by $44 \%$ in subjects with mild renal impairment $(\mathrm{CrCl}$ of $50-79 \mathrm{~mL} / \mathrm{min})$, by $52 \%$ in those with moderate renal impairment $(\mathrm{CrCl}$ of $30-49 \mathrm{~mL} / \mathrm{min})$, and by $64 \%$ in those with severe impairment $(\mathrm{CrCl}$ of $<30 \mathrm{~mL} /$ min). ${ }^{46}$ Increased plasma concentrations were associated with more potent pharmacodynamic effects including an inhibition of factor $\mathrm{Xa}$ activity and prolongation of the prothrombin time.

The ROCKET AF trial included patients with AF and moderate renal impairment $(26 \%$ of the study population with a $\mathrm{CrCl}$ of $30-49 \mathrm{~mL} / \mathrm{min}$ ) who received a dose of $15 \mathrm{mg} / \mathrm{d}$ and estimated that a $25 \%$ dose reduction would result in a similar exposure in patients with moderate renal impairment. In patients with moderate renal impairment, the rates of stroke and systemic embolism were higher as compared to those patients with a better renal function. The primary event rate in the intention-to-treat analysis was 2.95 per 100 patient-years with rivaroxaban $15 \mathrm{mg} /$ day, as compared with 3.44 per 100 patient-years with warfarin. Thus, rivaroxaban had no significant benefit in patients with moderate renal failure, as compared to warfarin. Major bleeding occurred more frequently in patients with renal impairment among all treatment groups. ${ }^{47}$ Rivaroxaban has not been studied so far in patients with severe renal impairment $(\mathrm{CrCl}<30 \mathrm{~mL} / \mathrm{min})$.

A meta-analysis also demonstrated that rivaroxaban and apixaban are more effective in stroke prevention together with a lower risk of bleeding in patients with AF and a normal to moderately reduced GFR. ${ }^{48}$

The EINSTEIN-DVT ${ }^{49}$ and EINSTEIN-PE ${ }^{50}$ studies analyzed rivaroxaban and warfarin in patients with VTE and deep venous thrombosis with pulmonary embolism and a $\mathrm{CrCl}$ of $30-49 \mathrm{~mL} / \mathrm{min}$ ( $8 \%$ and $10 \%$ of the study population, respectively). The risk of recurrent thromboembolism or thromboembolism-related death as well as the risk of bleeding were not different in both studies.

\section{Edoxaban}

The renal elimination of edoxaban is $50 \% .^{38}$ The HOKUSAIVTE trial analyzed edoxaban and warfarin in patients with symptomatic VTE. The $30 \mathrm{mg}$ once-daily dose was used in patients with estimated $\mathrm{CrCl}$ of $30-50 \mathrm{~mL} / \mathrm{min}$. A trend of a reduced rate of VTE recurrence or VTE-related death was present in edoxaban-treated patients with a moderate reduction in GFR ( $3 \%$ event rate in edoxaban-treated patients versus $5.9 \%$ for standard treatment). No difference appeared between edoxaban and warfarin regarding bleeding events in moderate renal impairment. ${ }^{51}$ In a phase 3 , multicenter, open-label, three parallel-group study over 12 weeks, patients with $\mathrm{AF}$ and a $\mathrm{CrCl}$ between 15 and $30 \mathrm{~mL} / \mathrm{min}$ received edoxaban $15 \mathrm{mg}$ once daily. This resulted in a similar risk of hemorrhage and plasma concentrations, as compared to the $30 \mathrm{mg}$ and $60 \mathrm{mg}$ doses in patients with normal renal function or moderate renal impairment with a $\mathrm{CrCl}>50 \mathrm{~mL} / \mathrm{min} .{ }^{52} \mathrm{~A}$ phase 1 , open-label, crossover study in patients on dialysis 
analyzed the pharmacokinetic profiles of edoxaban and showed that an additional dose of edoxaban is not required after HD if a single dose of $15 \mathrm{mg}$ is administered. ${ }^{53}$ Edoxaban is not removed through dialysis. Hemorrhages were not evaluated in this study. Finally, a meta-analysis demonstrated that edoxaban is more effective in stroke prevention together with a lower risk of bleeding in patients with AF and a normal to moderately reduced renal function. ${ }^{48}$

\section{Direct oral thrombin inhibitor Dabigatran}

As dabigatran is eliminated up to $80 \%$ through the kidneys, accumulation can easily occur in patients with CKD. Its halflife can increase from 12-17 hours in healthy individuals to 13-23 hours in patients with moderate renal impairment ( $\mathrm{CrCl} 30-50 \mathrm{~mL} / \mathrm{min}$ ) and up to $22-35$ hours in those with severe renal impairment $(\mathrm{CrCl}<30 \mathrm{~mL} / \mathrm{min}) .{ }^{54}$ Accordingly, an increase of the area under the curve of dabigatran of 1.5 times in patients with mild CKD to 3.2-6.3 times in patients with moderate to severe CKD as compared to patients with a normal renal function could be demonstrated. A further analysis of data from the RE-LY trial, which analyzed dabigatran versus warfarin in patients with AF including $24 \%$ of the study population with a $\mathrm{CrCl}<50 \mathrm{~mL} / \mathrm{min}$, showed that renal function had the most important effect on dabigatran plasma concentrations. ${ }^{55}$ This increase was more pronounced in patients receiving dabigatran $110 \mathrm{mg}$ twice daily (relative risk of 3.5 in patients with $\mathrm{CrCl}<50 \mathrm{~mL} / \mathrm{min}$ compared with patients with $\mathrm{CrCl}>80 \mathrm{~mL} / \mathrm{min}$ ) than in those receiving warfarin (respective relative risk of 2.3) ${ }^{56}$ Dabigatran should not be used in patients with a GFR below $60 \mathrm{~mL} / \mathrm{min}$, although the US Food and Drug Administration approved dabigatran $75 \mathrm{mg}$ twice daily in patients with a $\mathrm{CrCl}$ between 15 and 30 $\mathrm{mL} / \mathrm{min} .{ }^{57}$ The number of patients was small for each renal function group, and data from large-scale trials in patients with severe renal impairment are not available. Patients with an estimated glomerular filtration rate (eGFR) $>60 \mathrm{~mL} / \mathrm{min}$ should be monitored closely for their renal function. Dabigatran can be partly removed by dialysis, as 62\% (after 2 hours) and $68 \%$ (after 4 hours) of a $50 \mathrm{mg}$ dose were removed during a 4-hour dialysis session. ${ }^{58}$ Thus, dabigatran is not recommended for anticoagulation during HD.

\section{DOACs - patient selection and special considerations}

\section{Renal function}

Even in patients with mild/moderate reduction of the GFR, caution is warranted as kidney function can decline suddenly and rapidly due to acute kidney injury, particularly in the elderly. Thus, regular monitoring of renal function is mandatory in patients with CKD receiving DOAC. A survey of the European Heart Rhythm Scientific Initiatives Committee showed that of 41 centers, 95.1\% and $90.2 \%$ routinely evaluated renal function in AF patients at first presentation and during follow-up, respectively. ${ }^{59}$ Advanced CKD was reassessed in $31.7 \%$ of the centers only at $\geq 1$-year intervals. The use of oral anticoagulants in patients with mild/moderate CKD was guided by the individual stroke risk in most patients. No therapy, or aspirin, or left atrial appendage occlusion was used in $31 \%$ of the centers in patients with advanced CKD and a HAS-BLED $\geq 3$. VKAs were preferred in patients with severe CKD or under renal replacement therapy, while DOACs were used in patients with mild CKD, and apixaban in patients with moderate CKD.

Another fact has to be kept in mind when interpreting study data and transfering those data into clinical practice. Many randomized control trials (RCTs) used the Cockroft-Gault formula to estimate GFR and assign the patients to the respective CKD stages. However, in clinical practice, patients are nowadays evaluated using the CKD epi formula in most cases. This could lead to differences of the patients actually treated in comparison with the studied patients. ${ }^{60}$ The method used to estimate renal function can significantly influence the administered dose, especially in elderly patients. In a retrospective study, the use of the Cockroft-Gault equation instead of the abbreviated Modification of Diet in Renal Disease (MDRD) equation 4 resulted in significantly lower estimated renal function in patients $>65$ years of age. Data simulation showed that MDRD would result in a $25 \%$ higher mean dose of dabigatran. ${ }^{61}$

\section{Elderly patients}

Elderly patients have a lower GFR as compared to younger patients, as GFR physiologically declines with age and potential comorbidities such as arterial hypertension or diabetes mellitus reduce GFR even more in such patients. Furthermore, distribution volume and body weight can substantially vary as compared to younger patients. As the elimination of DOAC depends on the GFR, particularly elderly patients are prone to overdosing with the related safety problems. Data on the treatment of elderly patients with DOAC are lacking so far, particularly in those with an additional impairment of renal function.

A subgroup analysis of the RE-LY trial in patients with AF at risk for stroke demonstrated a higher risk for extracranial bleeding with dabigatran as compared to warfarin in patients 
older than 75 years, while this risk was lower in patients of age $<75$ years. ${ }^{56}$ The risk of intracranial bleeding was lower as compared to warfarin, irrespective of age. But the additional effect of renal impairment on the bleeding risk was not considered in this subgroup analysis. It should additionally increase the risk of hemorrhage. Thus, these data cannot be easily transferred to patients with renal failure.

Rivaroxaban was associated with more frequent stroke or systemic embolism and major bleeding events in patients aged $>75$ in the ROCKET AF study.

Apixaban led to more incidence of stroke or systemic embolism and major bleeding events in patients aged $\geq 75$ years compared with the $<65$ years age group in the ARISTOTLE study. The increase in the bleeding rate tended to be lower in the apixaban-treated patients compared to the warfarin-treated patients. ${ }^{36}$

On the other hand, efficacy outcomes with respect to stroke or systemic embolism were not affected by age in the randomized treatment studies in patients with $\mathrm{AF}$, such as the ENGAGE AF-TIMI 48 trial. ${ }^{38}$ The situation in patients with VTE is less clear, as the age of the participating patients was much lower as in the AF trials. Treatment with rivaroxaban showed a trend toward improved safety in patients aged $>75$ years, according to the EINSTEIN trials. ${ }^{62}$ Edoxaban had a trend toward higher efficacy in this patient group in the HOKUSAI-VTE trial, while its safety was not affected by age. ${ }^{51}$ Data regarding age and renal function in both trials are not available so far. Apixaban seems to be safe also in patients of an age $>75$ years. Due to its lower renal elimination apixaban should be preferred in older patients with a GFR between 30 and $60 \mathrm{~mL} / \mathrm{min}^{45}$

\section{Monitoring and safety}

A test accurately and precisely measuring the effect of DOACs is not routinely available so far. The anticoagulant effect of dabigatran can be measured using a dilute thrombin time assay or ecarin-based assay. Calibrated chromogenic anti-Xa assays can be used to analyze the effects of direct Xa inhibitors. ${ }^{63,64}$ If such tests are not available, thrombin time or activated partial thromboplastin time (APTT) can be used with limitations for dabigatran and the INR for the assessment of anti-Xa inhibitors. Furthermore, it is important to consider the time since the last dose, potential drug interactions, and also the renal and hepatic function.

So far, only idarucizumab has been approved as an antidote against dabigatran, which can also be removed by dialysis. ${ }^{65}$ Other antidotes such as andexanet alfa, a recombinant factor $\mathrm{Xa}$ variant that binds factor $\mathrm{Xa}$ inhibitors but lacks coagulant activity, as well as ciraparantag (PER977), a universal antidote targeted at reversing factor Xa inhibitors, are being evaluated in clinical studies at present. Moreover, monitoring of the drug effects is also difficult and not routinely established so far. ${ }^{66,67}$

\section{Drug and food interactions}

DOACs have only a few pharmacokinetic interactions of mild character with other commonly administered drugs. ${ }^{68}$ Rivaroxaban and dabigatran are substrates of the efflux transporter P-glycoprotein which is induced by rifampicin and inhibited by ketoconazole and dronedarone. ${ }^{69}$ Rivaroxaban and apixaban are also metabolized by the CYP3A4/5 enzyme that is inhibited by ketoconazole and ritonavir, for example. ${ }^{70}$ Thus, rivaroxaban should be avoided in patients receiving protease inhibitors or azole antifungal agents. Apixaban is also metabolized by CYP3A/5 and, to a minor part, by CYP1A2 that are inhibited by ketoconazole. ${ }^{71}$

The absorption of DOAC is also modified by coadministered substances such as proton pump inhibitors, which reduce the bioavailability of dabigatran, for example, by $12.5 \%$. This might be related to the increased gastric $\mathrm{pH} .{ }^{55}$ Omeprazole does not seem to interact with rivaroxaban. ${ }^{72}$ Rivaroxaban should be taken with food, which improves its absorption. ${ }^{73}$ Caution regarding an increased bleeding risk is warranted if either nonsteroidal anti-inflammatory drugs (NSAIDs) or antiplatelet agents are coadministered. A pooled analysis of the EINSTEIN-DVT and -PE studies showed an increased risk for major bleeding events during NSAIDs use compared with the major bleeding rate during non-use of NSAIDs, with a hazard ratio (HR) of 2.56 (95\% confidence interval [CI] 1.21-5.39) for rivaroxaban-treated patients. ${ }^{74}$ The use of antiplatelet agents together with dabigatran was associated with an increased risk of major bleeding. Dual antiplatelet therapy increased the bleeding risk (HR 2.31; 95\% CI 1.79-2.98) as compared to single antiplatelet therapy (HR 1.60; 95\% CI 1.42-1.82). The interaction between NSAIDs and antiplatelet agents with apixaban is not clear so far. Altogether, the coadministration of antiplatelet agents or NSAIDs in patients on DOACs should be avoided if possible.

\section{Summary}

Patients with CKD often have additional cardiovascular diseases such as AF, thromboembolic events, coronary artery disease, or peripheral vascular disease. Thus, anticoagulants, antiplatelet agents, or their combination are frequently prescribed to patients with CKD. As some of these agents are eliminated by the kidney, such agents might accumulate in 
patients with reduced renal function, leading to an increased number of bleeding episodes. Heparin can be used safely, while LMWH accumulate in patients with reduced renal function. VKA are particularly used in patients with severely reduced renal function, while DOAC should be avoided in such patients due to their potential to accumulate with declining renal function. Moreover, the lower the renal function is, the lesser are the benefits as compared to anticoagulation with VKA. Dose reductions are necessary in patients with moderate reduction of renal function. Due to lack of data, DOAC should be avoided in patients on dialysis. Altogether, CKD patients, particularly those with moderate to severe $\mathrm{CKD}$, require a clear indication for anticoagulation or antiplatelet therapy, an appropriate dose adaptation if necessary, as well as a regular monitoring of their renal function and antithrombotic therapy.

\section{Disclosure}

The authors report no conflicts of interest in this work.

\section{References}

1. Lutz J, Menke J, Sollinger D, Schinzel H, Thurmel K. Haemostasis in chronic kidney disease. Nephrol Dial Transplant. 2014;29(1):29-40.

2. Bauer A, Limperger V, Nowak-Gottl U. End-stage renal disease and thrombophilia. Hamostaseologie. 2016;36(2):103-107.

3. Wattanakit K, Cushman M, Stehman-Breen C, Heckbert SR, Folsom AR. Chronic kidney disease increases risk for venous thromboembolism. $J$ Am Soc Nephrol. 2008;19(1):135-140.

4. Boccardo P, Remuzzi G, Galbusera M. Platelet dysfunction in renal failure. Semin Thromb Hemost. 2004;30(5):579-589.

5. Kaufman JS, O'Connor TZ, Zhang JH, et al. Randomized controlled trial of clopidogrel plus aspirin to prevent hemodialysis access graft thrombosis. J Am Soc Nephrol. 2003;14(9):2313-2321.

6. Moal V, Brunet P, Dou L, Morange S, Sampol J, Berland Y. Impaired expression of glycoproteins on resting and stimulated platelets in uraemic patients. Nephrol Dial Transplant. 2003;18(9):1834-1841.

7. Pavord S, Myers B. Bleeding and thrombotic complications of kidney disease. Blood Rev. 2011;25(6):271-278.

8. Parikh AM, Spencer FA, Lessard D, et al. Venous thromboembolism in patients with reduced estimated GFR: a population-based perspective. Am J Kidney Dis. 2011;58(5):746-755.

9. Olesen JB, Lip GY, Kamper AL, et al. Stroke and bleeding in atrial fibrillation with chronic kidney disease. N Engl J Med. 2012;367(7):625-635.

10. Wilke T, Wehling M, Amann S, Bauersachs RM, Bottger B. [Renal impairment in patients with thromboembolic event: prevalence and clinical implications. A systematic review of the literature]. Dtsch Med Wochenschr. 2015;140(17):e166-e174. German.

11. Hoffmann P, Keller F. Increased major bleeding risk in patients with kidney dysfunction receiving enoxaparin: a meta-analysis. Eur J Clin Pharmacol. 2012;68(5):757-765.

12. Thorevska N, Amoateng-Adjepong Y, Sabahi R, et al. Anticoagulation in hospitalized patients with renal insufficiency: a comparison of bleeding rates with unfractionated heparin vs enoxaparin. Chest. 2004;125(3):856-863.

13. Dager WE, Kiser TH. Systemic anticoagulation considerations in chronic kidney disease. Adv Chronic Kidney Dis. 2010;17(5):420-427.

14. Harenberg J, Hentschel VA, Du S, et al. Anticoagulation in patients with impaired renal function and with haemodialysis. Anticoagulant effects, efficacy, safety, therapeutic options. Hamostaseolog 2015;35(1): $77-83$.
15. Holbrook A, Schulman S, Witt DM, et al. Evidence-based management of anticoagulant therapy: Antithrombotic Therapy and Prevention of Thrombosis, 9th ed: American College of Chest Physicians EvidenceBased Clinical Practice Guidelines. Chest. 2012;141(2 Suppl): e152S-e184S.

16. Jun M, James MT, Ma Z, et al. Warfarin initiation, atrial fibrillation, and kidney function: comparative effectiveness and safety of warfarin in older adults with newly diagnosed atrial fibrillation. Am J Kidney Dis. Epub 2016 Dec 17.

17. McCabe KM, Adams MA, Holden RM. Vitamin K status in chronic kidney disease. Nutrients. 2013;5(11):4390-4398.

18. Quinn LM, Richardson R, Cameron KJ, Battistella M. Evaluating time in therapeutic range for hemodialysis patients taking warfarin. Clin Nephrol. 2015;83(2):80-85.

19. Han KH, O’Neill WC. Increased Peripheral Arterial Calcification in Patients Receiving Warfarin. JAm Heart Assoc. 2016;5(1).pii: e002665.

20. Poterucha TJ, Goldhaber SZ. Warfarin and Vascular Calcification. Am J Med. 2016;129(6):635 e1-e4.

21. Tantisattamo E, Han KH, O'Neill WC. Increased vascular calcification in patients receiving warfarin. Arterioscler Thromb Vasc Biol. 2015; 35(1):237-242.

22. Chan KE, Lazarus JM, Thadhani R, Hakim RM. Warfarin use associates with increased risk for stroke in hemodialysis patients with atrial fibrillation. J Am Soc Neprol. 2009;20(10):2223-2233.

23. Wizemann V, Tong L, Satayathum S, et al. Atrial fibrillation in hemodialysis patients: clinical features and associations with anticoagulant therapy. Kidney Int. 2010;77(12):1098-1106.

24. Shah M, Avgil Tsadok M, Jackevicius CA, et al. Warfarin use and the risk for stroke and bleeding in patients with atrial fibrillation undergoing dialysis. Circulation. 2014;129(11):1196-1203.

25. Rosendaal FR, Cannegieter SC, van der Meer FJ, Briet E. A method to determine the optimal intensity of oral anticoagulant therapy. Thromb Haemost. 1993;69(3):236-239.

26. Schein JR, White CM, Nelson WW, Kluger J, Mearns ES, Coleman CI. Vitamin K antagonist use: evidence of the difficulty of achieving and maintaining target INR range and subsequent consequences. Thromb J. 2016;14:14.

27. Clark NP. Low-molecular-weight heparin use in the obese, elderly, and in renal insufficiency. Thromb Res. 2008;123(Suppl 1):S58-S61.

28. Crowther M, Lim W. Low molecular weight heparin and bleeding in patients with chronic renal failure. Curr Opin Pulm Med. 2007;13(5):409-413.

29. Schwartzenberg S, Lev EI, Sagie A, Korzets A, Kornowski R. The quandary of oral anticoagulation in patients with atrial fibrillation and chronic kidney disease. Am J Cardiol. 2016;117(3):477-482.

30. Szummer K, Gasparini A, Eliasson S, et al. Time in therapeutic range and outcomes after warfarin initiation in newly diagnosed atrial fibrillation patients with renal dyfunction. JAm Heart Assoc. 2017;6(3). pii: 004925.

31. Harel Z, Sood MM, Perl J. Comparison of novel oral anticoagulants versus vitamin $\mathrm{K}$ antagonists in patients with chronic kidney disease. Curr Opin Nephrol Hypertens. 2015;24(2):183-192.

32. Hijazi Z, Hohnloser SH, Oldgren J, et al. Efficacy and safety of dabigatran compared with warfarin in relation to baseline renal function in patients with atrial fibrillation: a RE-LY (Randomized Evaluation of Long-term Anticoagulation Therapy) trial analysis. Circulation. 2014; 129(9):961-970.

33. Hohnloser SH, Hijazi Z, Thomas L, et al. Efficacy of apixaban when compared with warfarin in relation to renal function in patients with atrial fibrillation: insights from the ARISTOTLE trial. Eur Heart J. 2012; 33(22):2821-2830.

34. Connolly SJ, Ezekowitz MD, Yusuf S, et al. Dabigatran versus warfarin in patients with atrial fibrillation. NEngl J Med. 2009;361(12):1139-1151.

35. Patel MR, Mahaffey KW, Garg J, et al. Rivaroxaban versus warfarin in nonvalvular atrial fibrillation. $N$ Engl J Med. 2011;365(10):883-891.

36. Granger CB, Alexander JH, McMurray JJ, et al. Apixaban versus warfarin in patients with atrial fibrillation. $N$ Engl J Med. 2011;365(11):981-992. 
37. Hori M, Matsumoto M, Tanahashi N, et al. Rivaroxaban vs. warfarin in Japanese patients with non-valvular atrial fibrillation in relation to age. Circ J. 2014;78(6):1349-1356.

38. Giugliano RP, Ruff CT, Braunwald E, et al. Edoxaban versus warfarin in patients with atrial fibrillation. N Engl J Med. 2013;369(22):2093-2104.

39. Bai Y, Chen H, Yang Y, et al. Safety of antithrombotic drugs in patients with atrial fibrillation and non-end-stage chronic kidney disease: metaanalysis and systematic review. Thromb Res. 2016;137:46-52.

40. Connolly SJ, Eikelboom J, Joyner C, et al. Apixaban in patients with atrial fibrillation. $N$ Engl J Med. 2011;364(9):806-817.

41. Harel Z, Sholzberg M, Shah PS, et al. Comparisons between novel oral anticoagulants and vitamin $\mathrm{K}$ antagonists in patients with CKD. J Am Soc Nephrol. 2014;25(3):431-442.

42. Harel Z, Mamdani M, Juurlink DN, et al. Novel oral anticoagulants and the risk of major hemorrhage in elderly patients with chronic kidney disease: A Nested Case-Control Study. Can J Cardiol. 2016;32(8):e17-e22.

43. Ando G, Capranzano P. Non-vitamin K antagonist oral anticoagulants in atrial fibrillation patients with chronic kidney disease: a systematic review and network meta-analysis. Int J Cardiol. 2017;231:162-169.

44. Mavrakanas T, Bounameaux H. The potential role of new oral anticoagulants in the prevention and treatment of thromboembolism. Pharmacol Ther: 2011;130(1):46-58.

45. Agnelli G, Buller HR, Cohen A, et al. Oral apixaban for the treatment of acute venous thromboembolism. N Engl J Med. 2013;369(9): 799-808.

46. Kubitza D, Becka M, Mueck W, et al. Effects of renal impairment on the pharmacokinetics, pharmacodynamics and safety of rivaroxaban, an oral, direct Factor Xa inhibitor. Br J Clin Pharmacol. 2010; 70(5):703-712.

47. Fox KA, Piccini JP, Wojdyla D, et al. Prevention of stroke and systemic embolism with rivaroxaban compared with warfarin in patients with non-valvular atrial fibrillation and moderate renal impairment. Eur Heart J. 2011;32(19):2387-2394.

48. Ahmad Y, Lip GY, Apostolakis S. New oral anticoagulants for stroke prevention in atrial fibrillation: impact of gender, heart failure, diabetes mellitus and paroxysmal atrial fibrillation. Expert Rev Cardiovas Ther. 2012;10(12):1471-1480.

49. Schulman S, Kearon C, Kakkar AK, et al. Extended use of dabigatran, warfarin, or placebo in venous thromboembolism. $N$ Engl J Med. 2013;368(8):709-718.

50. EINSTEIN Investigators; Bauersachs R, Berkowitz SD, et al. Oral rivaroxaban for symptomatic venous thromboembolism. N Engl J Med. 2010; 363(26):2499-2510.

51. Hokusai-VTE Investigators; Buller HR, Decousus H, et al. Edoxaban versus warfarin for the treatment of symptomatic venous thromboembolism. N Engl J Med. 2013;369(15):1406-1415.

52. Koretsune Y, Yamashita T, Kimura T, Fukuzawa M, Abe K, Yasaka M. Short-term safety and plasma concentrations of edoxaban in Japanese patients with non-valvular atrial fibrillation and severe renal impairment. C J. 2015;79(7):1486-1495.

53. Parasrampuria DA, Marbury T, Matsushima N, et al. Pharmacokinetics, safety, and tolerability of edoxaban in end-stage renal disease subjects undergoing haemodialysis. Thromb Haemost. 2015;113(4):719-727.

54. van Ryn J, Stangier J, Haertter S, et al. Dabigatran etexilate--a novel, reversible, oral direct thrombin inhibitor: interpretation of coagulation assays and reversal of anticoagulant activity. Thromb Haemost. 2010;103(6):1116-1127.

55. Liesenfeld KH, Lehr T, Dansirikul C, et al. Population pharmacokinetic analysis of the oral thrombin inhibitor dabigatran etexilate in patients with non-valvular atrial fibrillation from the RE-LY trial. $J$ Thromb Haemost. 2011;9(11):2168-2175.

56. Eikelboom JW, Wallentin L, Connolly SJ, et al. Risk of bleeding with 2 doses of dabigatran compared with warfarin in older and younger patients with atrial fibrillation: an analysis of the randomized evaluation of longterm anticoagulant therapy (RE-LY) trial. Circulation. 2011;123(21): 2363-2372.
57. Hariharan S, Madabushi R. Clinical pharmacology basis of deriving dosing recommendations for dabigatran in patients with severe renal impairment. J Clin Pharmcol. 2012;52(Suppl 1):119S-125S

58. Stangier J, Rathgen K, Stahle H, Mazur D. Influence of renal impairment on the pharmacokinetics and pharmacodynamics of oral dabigatran etexilate: an open-label, parallel-group, single-centre study. Clin Pharmacokinet. 2010;49(4):259-268.

59. Potpara TS, Lenarczyk R, Larsen TB, et al. Management of atrial fibrillation in patients with chronic kidney disease in Europe results of the European Heart Rhythm Association Survey. Europace. 2015; 17(12):1862-1867.

60. Fernandez-Prado R, Castillo-Rodriguez E, Velez-Arribas FJ, GraciaIguacel C, Ortiz A. Creatinine clearance is not equal to glomerular filtration rate and cockcroft-gault equation is not equal to CKD-EPI collaboration equation. Am J Med. 2016;129(12):1259-1263.

61. Hellden A, Odar-Cederlof I, Nilsson G, et al. Renal function estimations and dose recommendations for dabigatran, gabapentin and valaciclovir: a data simulation study focused on the elderly. BMJ open. 2013;3(4). pii: e002686.

62. Mitchell AP, Conway SE. Rivaroxaban for treatment of venous thromboembolism in older adults. Consult Pharm. 2014;29(9):627-630.

63. Baglin T, Hillarp A, Tripodi A, Elalamy I, Buller H, Ageno W. Measuring Oral Direct Inhibitors (ODIs) of thrombin and factor Xa: a recommendation from the Subcommittee on Control of Anticoagulation of the Scientific and Standardisation Committee of the International Society on Thrombosis and Haemostasis. J Thromb Haemost. 2013;11:756-757.

64. Samuelson BT, Cuker A, Siegal DM, Crowther M, Garcia DA. Laboratory assessment of the anticoagulant activity of Direct Oral Anticoagulants (DOACs): a systematic review. Chest. 2017;151(1):127-138.

65. Gottlieb M, Khishfe B. Idarucizumab for the reversal of dabigatran. Ann Emerg Med. Epub 2017 Jan 19.

66. Bertoletti L, Ollier E, Duvillard C, et al. Direct oral anticoagulants: current indications and unmet needs in the treatment of venous thromboembolism. Pharmacol Res. 2017;118:33-42.

67. Mlodawska E, Tomaszuk-Kazberuk A, Lopatowska P, Musial WJ, Malyszko J. Management of patients with atrial fibrillation and chronic kidney disease in light of the latest guidelines. Pol Arch Med Wewn. 2016;126(5):353-362.

68. Mavrakanas TA, Samer C, Fontana P, Perrier A. Direct oral anticoagulants: efficacy and safety in patient subgroups. Swiss Med Wkly. 2015;145:w14081.

69. Pfeilschifter W, Luger S, Brunkhorst R, Lindhoff-Last E, Foerch C. The gap between trial data and clinical practice -- an analysis of case reports on bleeding complications occurring under dabigatran and rivaroxaban anticoagulation. Cerebrovasc Dis. 2013;36(2):115-119.

70. Walenga JM, Adiguzel C. Drug and dietary interactions of the new and emerging oral anticoagulants. Int J Clin Pract. 2010;64(7):956-967.

71. Carreiro J, Ansell J. Apixaban, an oral direct Factor Xa inhibitor: awaiting the verdict. Expert Opin Investig Drugs. 2008;17(12):1 937-1945.

72. Moore KT, Plotnikov AN, Thyssen A, Vaccaro N, Ariyawansa J, Burton PB. Effect of multiple doses of omeprazole on the pharmacokinetics, pharmacodynamics, and safety of a single dose of rivaroxaban. J Cardiovasc Pharmacol. 2011;58(6):581-588.

73. Wang Y, Bajorek B. New oral anticoagulants in practice: pharmacological and practical considerations. Am J Cardiovasc Drugs. 2014; 14(3):175-189.

74. Davidson BL, Verheijen S, Lensing AW, et al. Bleeding risk of patients with acute venous thromboembolism taking nonsteroidal anti-inflammatory drugs or aspirin. JAMA Intern Med. 2014;174(6):947-953.

75. Diener HC, Aisenberg J, Ansell J, et al. Choosing a particular oral anticoagulant and dose for stroke prevention in individual patients with nonvalvular atrial fibrillation: part 2. Eur Heart J. 2017;38(12):860-868.

76. Suarez Fernandez C, Formiga F, Camafort M, et al. Antithrombotic treatment in elderly patients with atrial fibrillation: a practical approach. BMC Cardiovasc Disord. 2015;15:143. 
The International Journal of Nephrology and Renovascular Disease is an international, peer-reviewed open access journal focusing on the pathophysiology of the kidney and vascular supply. Epidemiology, screening, diagnosis, and treatment interventions are covered as well as basic science, biochemical and immunological studies. The manuscript management system is completely online and includes a very quick and fair peer-review system, which is all easy to use. Visit http://www dovepress.com/testimonials.php to read real quotes from published authors.

Submit your manuscript here: https://www.dovepress.com/international-journal-of-nephrology-and-renovascular-disease-journal 